\title{
Consistency, Protection, Responsibility
} Revisiting the Debate on Selective Humanitarianism

\author{
Noele Crossley \\ Department of International Development, University of Oxford, \\ Oxford, United Kingdom \\ noele.crossley@qeh.ox.ac.uk
}

\begin{abstract}
Selective humanitarianism, it has been argued, may be condonable, or even preferable. Several arguments have been proffered in support of these views. This article revisits these arguments in light of the emergence of a discourse of protection and responsibility that now incorporates a wider spectrum of protection measures available to agents, of which armed intervention is but one. Consistency is an essential characteristic of ethics and the law-inconsistent practice diminishes the prospects of the development of norms of protection and associated practices and institutions. Furthermore, inconsistent practice means that fewer people receive protection from egregious violations of human rights. If the principles associated with human protection and humanitarianism are to become established norms of international society, international policy must be coherent, and international practice must be consistent.
\end{abstract}

\section{Keywords}

selective intervention - consistency - norms - international law - humanitarianism human protection - responsibility to protect - civilian protection

\section{Introduction}

The present discourse of responsibility suggests that, when states disintegrate and societies break apart, international actors have a collective responsibility to provide protection where governments no longer do. However, the agents tasked with providing this protection-states, international organizations, regional and subregional bodies, and even humanitarian aid organizations 
and civil society actors-are known to respond selectively and inconsistently to humanitarian emergencies. While some responses are robust, others are weak. While some responses are in line with UN Charter obligations and other accepted principles, others are not.

Military intervention, where it occurs, is almost always justified-at least in part-on humanitarian grounds. This has not always been the case. ${ }^{1}$ Today, humanitarian objectives shape perceptions about appropriate responses to grave violations of rights and human suffering. Questions no longer revolve around whether international actors-principally states and the UN, but also including humanitarian agencies-have a responsibility toward vulnerable populations, but around whose responsibility it is ${ }^{2}$ or what this responsibility entails. ${ }^{3}$ The theme of responsibility ${ }^{4}$ and the object of protection- the individuals, and the communities on which their livelihood critically dependshave become central in the international discourse in the humanitarian domain. Practices, equally, have changed. The humanitarian domain is characterized by increasing professionalization and organization, ${ }^{5}$ and with it, arguably, heightened expectations about the consistency of collective responses to humanitarian crises.

Although questions around responsibility, implementation, and accountability are subject to political considerations, they reveal a theoretical standpoint that is premised on the assumption that rules and laws matter-that ethical and legal principles should be applied to determine the right course of action in a given situation. These questions also suggest that there is a desire for principles that can offer answers that are not provisional, but that are sufficiently stable to condition our expectations about appropriate behavior. This applies to norms that have been formalized through their articulation as lawthat is, regulative norms that determine responses to norm-violating behavior, ${ }^{6}$ as well as norms constituted through social practice.

1 Wheeler 2000.

2 Pattison 2008.

3 For a general discussion, see Bellamy and Williams 2011; for a discussion of the threshold for action as outlined in the World Summit Outcome Document, see Bellamy 2006; and for a discussion of appropriate responses, see Bellamy 2008 and Pattison 2018.

4 The Responsibility to Protect is a political principle with norm potential, and the predominant view is that it does not establish new obligations, although it may allow international actors to reinterpret existing sources of international law. For a discussion of the principle's legal status, see Glanville 2012.

5 Michael Barnett refers to a club of humanitarian practitioners. Barnett 2019.

6 Björkdahl 2002. 
The existing literature on selectivity and inconsistency has, for the most part, been concerned with coercive measures, particularly military intervention. In this context, arguments that inconsistency may be necessary, or even that it may be preferable, have been dominant. Lea Brilmayer, Chris Brown, Abram Chayes and Antonia Handler Chayes, Lori Fisler Damrosch, Edward Luttwak, Robert Pape, Jerome Slater and Terry Nardin, and Jennifer Szende, as outlined further on, have all articulated arguments in defense of inconsistency. However, I argue that the emergence of a discourse of protection and responsibility, associated with the development of a human protection regime ${ }^{7}$ comprising the "protection of civilians," "human security," and the "Responsibility to Protect," means that arguments in favor of inconsistency are less compelling today than they may have been in the past. The contemporary discourse of protection and responsibility raises greater expectations about international duties, and is more comprehensive in its approach, casting a new light on the traditional objections to consistent humanitarianism. Consequently, it is worth revisiting the traditional arguments in defense of inconsistency. Do these arguments retain their validity in light of the new protection discourse?

This article is organized as follows. First, I engage with terminology and definitions, discussing meanings of coherence and consistency and how these concepts can be applied to practice with regard to both process (the principles that guide decision-making on humanitarian action, in other words deontological questions) and outcomes (consistency from a substantive perspective, in other words consequentialist arguments). Next, I provide a brief overview of the emergence of a discourse of protection and responsibility, and how this discourse has shifted normative expectations. Following that, I revisit the traditional objections to consistency. I contrast these arguments with the aspirational position that has been marginalized in the academic literature. The aspirational position is compatible with the idea that a prudential use of force is necessary - but not with the idea that there is a moral justification for the unequal distribution of protection.

The idea of consistency as a normative imperative holds across policy domains and includes the seemingly less contentious area of the provision of humanitarian relief, but arguments about selectivity and consistency originate in the humanitarian intervention debate of the immediate post-Cold War era. I subject four traditional arguments in defense of inconsistency to closer scrutiny on their own terms and in light of the emergence of the protection discourse. I suggest that, in light of the protection discourse that is more focused in

7 The term human protection was first used in a speech by Ban Ki-Moon in 2011. Ban 2011. Alex Bellamy describes the emergence and scope of the human protection regime. Bellamy 2016. 
its objectives (protecting individuals) and more comprehensive in its approach (with a wide range of measures at agents' disposal), the traditional objections to inconsistency are less compelling. It is worth noting that many of those who had previously argued in defense of inconsistency may no longer object to consistency. However, there is as yet no academic treatment of normative arguments in defense of consistency in the new context. I conclude the article with a summary of arguments in defense of consistency.

\section{Consistency, Inconsistency, and Selective Intervention}

There are two ways in which the term consistency can be understood: first, in the Aristotelian sense of coherent, logical, and noncontradictory as a whole 8 and, second, in the sense of an absence of aberration. The dictionary definition of consistency defines the term as "being the same-the quality of always behaving or performing in a similar way, or of always happening in a similar way." 9 The first interpretation of the term (conceptual, or ontological consistency), in the Aristotelian sense of whole and coherent, implies that a concept or theory is logically sound, and that there are no inherent contradictions. In what follows, I refer to this as "coherence." Consistency thus defined, within legal philosophy, assumes that the law is necessarily consistent in the sense that no two norms can be valid simultaneously. ${ }^{10}$ If one assumes that international society is governed by international law-albeit a soft form of law-then it is possible to assess the degree of coherence of the law (i.e., the extent to which it contains competing and/or contradictory norms). When norms are inconsistent, this is referred to as "norm conflict."1 For example, there may be ambiguity about the extent to which UN Charter obligations prevail over conflicting obligations under other international agreements. ${ }^{12}$ One of the defining characteristics of international law is that it lacks coherence, at least when compared with domestic law. ${ }^{13}$

8 Aristotle 1933.

$9 \quad$ Cambridge Dictionary 2019.

10 For example, Hans Kelsen suggests that all of the norms within a given legal system are rooted in a "basic norm," which itself must derive from natural law (i.e., there is no "higher" explanation or authorization of the norm). Kelsen 1967, chap. 1.

11 Vranes 2006, 3.

12 For example, AlJedda and Behrami and Saramati, see Milanovic 2009, 79-86.

13 The International Law Commission, aware of the fact that international law is especially prone to inconsistency, published a report on the topic. International Law Commission 2006. 
The second interpretation of consistency pertains to the way in which principles and rules are applied. This understanding of consistency can be used in two distinct ways when discussing the legitimacy of human protection practice. It can stand for the absence of selectivity: the application of norms is consistent when similar cases are treated similarly. Again, a domestic analogy is helpful. "The rule of law requires that laws be applied equally, without unjustifiable differentiation. The courts of equity have long since embraced the principle that decisions must not vary ... and the law of precedent seeks to ensure, inter alia, that like cases are treated alike."14 The central normative argument in defense of consistency understood as absence of selectivity is that "inconsistency is one of the most frequent manifestations of unfairness that a person is likely to meet. Often there are distinctions which justify the difference in treatment, but sometimes there is no apparent distinction."15 In terms of protection responsibilities, this definition of consistency means that international actors tasked with delivering protection do so without fail, so that all those in need of protection receive it. This understanding of consistency means that that protection ought not to be meted out selectively. Inconsistency constitutes a form of disrespect if it results from double standards or hypocrisy; ${ }^{16}$ for example, if protection agents act militarily or diplomatically to prevent atrocities in one case, but not another, or if they provide humanitarian relief to certain populations during complex emergencies, but not to others similarly in need of relief, all else being equal. All populations in need should receive protection and, in that sense, international agents need to respond consistently. However, international practice is presently inconsistent-Alex Bellamy refers to this as "gaps in coverage" of the protection regime. ${ }^{17}$

\section{Steyn 1997, 22.}

15 Steyn 1997, 22.

16 I am grateful to James Pattison for raising this point. (Personal communication, March 2019). The difference between double standards and hypocrisy is explained well, with examples, in Fabre 2018, chap. 6. Double standards are when agents criticize behavior, but engage, or have previously engaged, in this behavior themselves, and excuse the behavior on other grounds. Hypocrisy is a situation in which agents are guilty of the same behavior, but deny partaking in the behavior. For example, an agent with protection responsibilities may be accused of double standards when responding differently to different cases of humanitarian emergency. The accusation may be justified or unjustified. It may be justified if the cases were sufficiently similar to merit equal treatment, but it would be unjustified if cases were different, either qualitatively or in terms of the magnitude and scale of the crisis - or both. On the other hand, protection agents would be acting hypocritically if they endorsed protection principles, but then failed to act in line with these principles.

17 Bellamy 2016, 16. Bellamy outlines five gaps: gaps in coherence, substantive gaps, geographic coverage gaps, gaps between expectations and capabilities, and agency gaps given the lack of articulation of responsibilities assigned to nonstate actors. 
Second, consistent application of principles means acting in line with principles - that is, the avoidance of aberration from international law-for example, the requirement that the use of force be authorized by the Security Council. Consequently, consistency thus defined means that collective responses are consistent with international principles - which does not necessarily require, or even call for, similar responses across cases. Given cases are usually very different the most appropriate responses for the realization of protection objectives will vary from case to case. Both of these definitions of consistency are relevant to this discussion.

The literature thus far has largely assumed that the consistent application of principles may produce inconsistent outcomes (treating unlike cases alike could prove detrimental to outcomes in terms of achieving protection if the means of doing so were not appropriate or served to make a bad situation worse) or, vice versa, that achieving positive outcomes consistently requires selective responses and inconsistent measures (responses ought to be tailored to case and context). However, the discourse of protection and responsibility has produced ideas that have reframed the way we think about intervention today. The human protection regime is more comprehensive, and more refined, than it was when the idea of "humanitarian intervention" emerged following the end of the Cold War. Given the wider range of measures at the disposal of actors, and the wider range of actors involved - comprising not just states, but a host of other relevant actors, including international organizations, regional organizations, and an array of humanitarian and civil society organizationsresponding prudently no longer means responding selectively.

What explains the support for arguments in defense of inconsistency? These arguments originate from the debate on the use of force on humanitarian grounds but, as I argue below, are less compelling today given a protection discourse in which the referent objects - the individuals, and the communities on which their livelihoods depend - are in the foreground, and the means of achieving protection are comprehensive, including noncoercive and nonmilitary coercive measures. The following section outlines the ideas that emerged in the context of the protection discourse and the way they have reframed the way we think about intervention today. Following this, I outline the aspirational position in favor of consistency and contrast this with traditional arguments in defense of inconsistency, ${ }^{18}$ and discuss the extent to which the latter remain compelling in light of the new discourse.

18 The defense of inconsistency has been limited to the intervention debate- to my knowledge, no one has ever explicitly argued for selective humanitarian relief - but the question of the extent to which protection can be apolitical, or even antipolitical, applies to the pro- 


\section{The Emergence of a Discourse of Protection and Responsibility}

The four traditional objections to consistency were raised in the context of the humanitarian intervention debate of the 199os, in which military intervention was perceived as the primary means of addressing conflict and humanitarian emergencies. How these arguments fare under a wider protection principle that encompasses a host of noncoercive and nonmilitary coercive measures, including diplomacy, sanctions, aid, and humanitarian relief, will be discussed further on. Prior to doing so, however, I provide a brief history of the emergence of the protection discourse, and the way it has begun to shape international perceptions about appropriate responses to humanitarian emergencies. The protection discourse, I suggest, has had significant implications in terms of perceptions within the epistemic community, as well as beyond, about appropriate responses to egregious violations of human rights and responses to complex humanitarian emergencies. I begin by outlining the antecedents of the new discourse of protection and responsibility and the way that the discourse relates to international practice - the actual track record of relevant actors' responses to conflict and complex humanitarian emergencies.

The emergence of the protection discourse is characterized by the development of concepts that have as their referent object the individual. The objective, within this new understanding, is the protection of the individual and communities, rather than national security and the defense of the state. The new discourse began to take shape after the end of the Cold War, throughout the 199os, and gained further traction throughout the 2000 s. ${ }^{19}$ The initial impetus for these changes resulted from the fall of the Iron Curtain, although its early antecedents date back to the Cold War era. Relevant in this context is the francophone debate on "le droit d'ingérence," and the subsequent wider reflections on the extent to which humanitarianism ought to be premised on neutrality. Since the Cold War came to an end, Boutros Boutros-Ghali's An Agenda for Peace ushered in a new era of "robust peacekeeping"; Mahbub ul Haq's conceptualization of "human security" in the 1993 and 1994 reports of the UN Development Programme provided scholars and policymakers with a new framework for thinking about security; and "sovereignty as responsibility," a phrase coined by Francis Deng in the context of protecting internally displaced persons, heralded a new way of thinking about state responsibility.

vision of humanitarian relief as it does to intervention, and in that sense the debate has implications beyond the narrow focus on the use of force.

Crossley 2016. 
Changes in public attitudes toward protection consolidated further throughout the 2ooos. "Human security," the "protection of civilians," and the "responsibility to protect" became important concepts shaping the ways in which scholars, policymakers, and practitioners understood international affairs, conflict and humanitarian crises, and their own roles as actors with certain responsibilities in relation to these. In unison, these principles did not just propagate the idea that the individual ought to be the key object of protection, but also indirectly —or directly, as in the case of principle of the Responsibility to Protect-suggested that protecting individuals constitutes a responsibility, rather than merely a discretionary right. All of these principles also had profound implications for the interpretation of the norm of state sovereignty and were intended to reconfigure its relationship with human rights norms. This had been the explicit objective of the International Commission on Intervention and State Sovereignty (ICISS), which developed the Responsibility to Protect principle. ${ }^{20}$ The commission suggested that human rights protection could be reconciled with respect for state sovereignty by understanding state sovereignty as contingent on the ability and willingness of the state to protect the human rights of individuals within its jurisdiction.

In seeking to mediate between seemingly contradictory norms, the architects of the principle aimed to influence customary international practice. The ideas emerging out of the consultations reflected growing discontent with a system premised on norms that understood state sovereignty as shielding domestic actors from punitive or preventative coercive humanitarian action. Norm proponents for the Responsibility to Protect attempted to chart a path out of this quandary. In concrete terms, the aim was twofold: to develop a framework for principles-guided responses on the one hand, and to put in place the institutional framework for the robust implementation of these principles on the other. In effect, the norm proponents were promoting consistency in the Aristotelian sense (coherence, or a reduction in ambiguity of international principles), as well as consistency in the discharge of these responsibilities (reducing selectivity). Consistent implementation would require responses

20 International Commission on Intervention and State Sovereignty 2001. Gareth Evans 2004 outlines how "every one of the big cases [Somalia, Rwanda, Srebrenica and Bosnia, as well as Kosovo] generated major international controversy — usually too late to be useful and never enough to settle the issue of principle once and for all." 79. He suggests that Kofi Annan played an important role as a norm entrepreneur: "[Annan was] one of those who has tried hardest to get sense and coherence into it all. Deeply troubled by the issues and the inconsistency of the international response ... he challenged the General Assembly to find a way through these dilemmas" (79). 
that were consistent in terms of being in line with principles of international law, as well in terms of the full provision of protection to all populations in need.

However, collective responses to humanitarian emergencies remain inconsistent. Even in the cases in which it is widely agreed that the "manifestly failing" threshold, according to the Responsibility to Protect principle has been met, or where there have been significant reasons to believe that the commission of mass atrocities was imminent, collective responses have been inconsistent. ${ }^{21}$ Selective responses and inconsistencies continue to characterize international responses, and the structural factors contributing to a historical record of inconsistency, including the setup of the UN Security Council, ${ }^{22}$ remain in place, although by some accounts the emerging international human protection regime can be credited with a reduced incidence of mass atrocities in recent decades. ${ }^{23}$ In any case, the discourse of responsibility has begun to change international perceptions about appropriate responses to humanitarian emergencies, as well as expectations about the consistency of those responses. Despite the gaps in implementation so far, the new discourse may improve the prospects for more consistent international responses in the future-as Jennifer Welsh suggests, the "issue of selectivity that has dogged humanitarian intervention may wane in the future."24

Revisiting the Objections to Consistency in Light of the Protection Discourse

Given that an aspiration toward consistency appears to be innate in our moral grammar, it is somewhat surprising that the normative scholarship on humanitarian intervention, when it emerged in the international discourse, ${ }^{25}$ leaned

21 Labonte 2012. Other empirical research has also established that international responses to large-scale humanitarian suffering, more broadly, has been selective; see Binder 2009. Binder's empirical analysis shows that UN agencies and humanitarian nongovernmental organizations responded to all of the humanitarian crises (armed conflict, displacement, hunger, disease, and human rights violations) between 1991 and 2004. An international response-defined as the presence of at least one of either a peacekeeping mission, economic sanctions, or military intervention —-was present in twenty out of the twenty-seven cases.

22 Hehir 2013.

23 Bellamy 2016.

24 Welsh 2002, 518.

25 On the emergence of humanitarian justifications for intervention, see Wheeler 2000. 
toward an assumption that consistency was a moral standard that international actors-predominantly states, in the traditional thinking-ought to aspire to, but that could not be realized in practice. The main area of contention was not whether consistency was desirable, but the degree of pragmatism that ought to be allowed given the structure of international society. Somewhere between order and chaos, and hierarchy and anarchy, humanitarian intervention needed to operate in a principled, yet workable, way. How far ought humanitarian action be constrained by considerations of principle, in the absence of the structures to support them? On this, opinions have diverged.

In theoretical terms, support for, or objections to, consistent approaches to humanitarian intervention are not necessarily congruent with existing typologies of theories, including cosmopolitanism and communitarianism. It is thinkable that cosmopolitans could defend pragmatic humanitarianism, and that communitarians could argue in favor of consistency. Typically, however, cosmopolitans tend to favor consistency, on the grounds that ethical principles ought to be applied universally; whereas communitarians, who regard duties and obligations as owed to an agent's own community in the first instance because that is the way social life is organized, support pragmatic approaches. Arguments for and against selective humanitarianism fall into either of two categories: in the first category, unqualified support for consistent humanitarianism, which I refer to as the "aspirational position"; and in the second, varying degrees of support for pragmatism.

"Consistency is essential," Kofi Annan argues in "Two Concepts of Sovereignty," an article in The Economist that retrospectively serves as a hallmark for the emergence of the new discourse on humanitarianism. ${ }^{26}$ The position represents the aspirational default position, embodied in the policy-oriented texts produced by the UN and its affiliated and supportive organizations. This position is rarely represented in the academic literature, ${ }^{27}$ for the obvious reason that the academic texts are usually based on the recognition that structural and exogenous factors unrelated to motive and intent- strategic interests and geopolitical factors, as well as lack of capacity-inhibit consistent collective responses. Consequently, the aspirational position is mostly represented in policy texts or included as an afterthought toward the end of academic papers on other matters, but it is relevant as it expresses a principled position derived

\footnotetext{
26 Annan 1999, 3.

27 Kieran Oberman is an exception here. Oberman argues that "states are required to wage the wars they are permitted to wage ... considerations of cost can only render war impermissible, not optional." Oberman 2015, 284.
} 
from universalist, solidarist principles that should, as I argue below, serve as the basis of ethical reasoning about appropriate responses to humanitarian emergencies.

In stark contrast to the aspirational position, the principled defense of selective intervention suggests that inconsistency may be acceptable, or even desirable. The position is anchored in the humanitarian intervention debate and represented in four distinct arguments: first, about the preferability of a discretionary right over a definite duty, given limited resources and lack of capacity; second, about the implications of a doctrine of military intervention for international order; third, about moral agency — the idea that prudential decisionmaking requires inconsistency; and, fourth, about a potential moral hazard arising from predictable intervention - the idea that predictable international responses can spur domestic unrest, causing adverse effects. These arguments are briefly outlined below. ${ }^{28}$ I discuss these arguments on their own terms and in light of the protection discourse. Have the traditional objections to consistency become obsolete in light of the new discourse of protection and responsibility?

\subsection{Discretionary Right}

Given the absence of an authority to assign responsibilities and enforce compliance, the first argument is based on the premise that all forms of humanitarianism constitute a discretionary right rather than a definite duty-in other words, a form of charity. The need for charity derives from the need to distribute scarce resources - in this case, states' limited capacities for protection intervention. The essence of charity is that it is, by definition, voluntary, affording agents a degree of autonomy they would not enjoy if protection were conceived of as a duty. ${ }^{29}$ Protection conceived of as charity entails no entitlement on the part of the protectee. Agents are not bound by duty, in the absence of assigned responsibilities, to make individual sacrifices to meet collective protection responsibilities.

The first objection to consistency, therefore, is that, given the structure of international society, selectivity is unavoidable. Slater and Nardin argue that, although the moral justification for intervention may supersede the principles of nonintervention, "the practical constraints on armed intervention are such that it can never be more than an exceptional remedy."30 Mark Evans concludes that "genuine and substantial discretion in the discharge of such duty may

28 These positions are outlined in Brown 2003, 31.

29 Although Peter Singer views charity as a duty. Singer 1972.

30 Slater and Nardin 1986,86 , quotation from abstract. 
well be unavoidable in particular under the global institutional circumstances in which we presently find ourselves." ${ }^{11}$ Brilmayer as well as Chayes and Handler Chayes similarly argue that selectivity is unavoidable, given limited resources. ${ }^{32}$ While individual donations may be commendable and effective, this action cannot be universalized, given limited resources. However, "few would make the ideal the enemy of the good," Thomas Weiss suggests, "by insisting that humanitarian intervention must occur whenever and wherever a crisis exists or not at all."33 Charity is, arguably, better than no remedial action at all. ${ }^{34}$

Also defending the "selectivity as necessity position" is Damrosch. She takes this argument one step further, suggesting that in the absence of institutional structures that can facilitate the execution of the law in a way that mirrors policing at the domestic level, it is "inevitable, possibly even preferable, for responses to international crises to unfold selectively, when those who have the capability to respond also have the motivations for undertaking the burdens of intervention." ${ }^{35}$ In a similar vein, Daphné Richemond suggests that "given the present state of the international system, the codification of a precise norm may not be preferable to the ambiguous regime currently in place, ${ }^{36}$ adding the usual qualification that "ideally, unilateral humanitarian intervention should be circumscribed within a clear legal framework, which would promise consistency and predictability."37

The classical rebuttal of the argument comes in the form of the domestic analogy. Brilmayer, for example, suggests it is "interesting that one does not hear the argument made in the domestic context that because the police could not possibly enforce all of the laws one hundred percent, they should have complete discretion to enforce it only in those cases where they feel like doing so."38 She also suggests that in the domestic context resources are similarly insufficient: "While police have a great deal of discretion to enforce the law or not ... this does not mean that we feel that they are entitled to make such deci-

$31 \quad$ M. Evans 2002, 134, emphasis in original.

32 Brilmayer 1995; Chayes and Handler Chayes 1995.

33 Weiss 2007, 18.

34 Chris Brown uses an analogy to illustrate the point - should one give money to sellers of street papers, even though individual donations are entirely discretionary and arbitrary, and unlikely to address the causes of the problem? Brown 2003, 229.

35 Damrosch 2000, 414.

36 Richemond 2003, 46.

37 With the usual reference to "conditions [which] simply do not exist for the realization of the strict normative approach" it was necessary to wait "until the time becomes ripe for the adoption of a stricter normative approach." Richemond 2003, 46.

Brilmayer 1995, 966. 
sions either on self-interest or on whim."39 However, the domestic analogy is an imperfect one. Even within states' jurisdictions, inconsistencies abound-the law is sometimes arbitrary, ${ }^{40}$ and charity replaces the provision of welfare by the state. ${ }^{41}$ However, there still should be consistency in the sense that agentsstates, in the traditional thinking - ought to use the limited resources available to them in such a way as to ensure that they are used where they are needed most.

Furthermore, the changed international normative environment casts a different light on these questions. By widening the range of protection agents, expanding the range of conceivable protection measures, and narrowing the protection focus to individuals and communities, consistent protection is no longer merely aspirational but has become a real policy objective. While the humanitarian intervention discourse recognized intervention as an exceptional response in exceptional circumstances, ${ }^{42}$ the protection discourse has introduced the idea that "sovereignty entails responsibility," altering expectations about collective responses to humanitarian emergencies. ${ }^{43}$ Louise Arbour, for example, suggests the responsibility to protect is in line with an existing duty of care toward vulnerable populations. ${ }^{44}$ Protection is no longer seen as a form of charity, but as a duty that is shared among international agents, including, but not limited to, states. A wider range of measures at agents' disposal distributes the burden of responsibility further. ${ }^{45}$ Arguably, the protection discourse has transformed perceptions about protection intervention, popularizing the notion that responding to humanitarian emergencies is no longer a discretionary right, but a duty.

39 Brilmayer 1995, 966.

40 Brown describes inconsistency of treatment with regard to the legalization of different forms of drugs-for example, cannabis, cocaine, and heroin are outlawed, while tobacco and alcohol are not, even though the claim that these drugs are less harmful is disputable. See Brown 2003, 40-41.

41 Brown 2003, 41. Should one give money to sellers of street magazines?

42 For example, Adam Roberts 2000 suggests that "it is questionable whether humanitarian intervention should be conceived of as a 'right'" (3) and, further, that "advocacy of a general duty to intervene presupposes the right to do so" (50).

43 Louise Arbour 2008, for example, argues that "the responsibility to protect norm is part and parcel of the new vision of human security that the Summit of the World's leaders in 2005 endorsed" (457), and that the doctrine "holds enormous promise for the extension of the protective reach of the law" (458), although Arbour recognizes that "consensus on how and when to activate it ... remains elusive" (458).

44 Arbour 2008.

45 For a summary of the development of the principle to encompass a wider spectrum of measures, see Kikoler 2009. 
If we assume that the protection discourse has indeed established a duty of protection from egregious human rights violations, then the question arises of whether protection is ever supererogatory; in other words, whether protection responses can be discretionary in that they exceed duties of agents who have already acted in line with assigned protection tasks or proportionate capacity. ${ }^{46}$ James Pattison suggests that duties to a protectee are not supererogatory, merely that there are conflicting duties owed to vulnerable populations on the one hand, and duties owed to one's own group members on the other hand. ${ }^{47}$ The expanded landscape of agents and means of protection may make it easier for agents to reconcile these duties. A wider range of agents, including international organizations, regional organizations, humanitarian agencies, and civil society organizations means that protection responsibilities, and corollary duties, are distributed more widely. A wider range of protection measures, including sanctions and diplomacy, means that agents are more able to reconcile competing duties. This, in turn, has implications for arguments in defense of selectivity. A discourse of collective protection responsibility, encompassing a wider range of agents and a comprehensive framework of protective measures, stands in opposition to the idea that selective protection is condonable.

\subsection{International Order}

The second argument in defense of inconsistency suggests that the codification of humanitarian intervention undermines the default norm against aggression, a principle commonly regarded as a normative bedrock of international order. Pape argues that an emerging practice of military intervention will corrode norms of state sovereignty, undermining international order. ${ }^{48}$ In a similar vein, Luttwak argues that, given the number of potential cases for intervention, the consistent implementation of protection norms would result in expansive UN protectorates and the loss of independence for many states. ${ }^{49}$ Pluralists regard intervention as an exceptional measure in exceptional circumstances. An analogy can be drawn with euthanasia, which is generally prohibited to prevent misuse..$^{50}$ While the argument is compelling in the context of humanitarian intervention - the use of force on human protection grounds-the defense of selectivity is less compelling when the objectives are limited, the available

\footnotetext{
46 On supererogatory action see, for example, Fabre 2018.

47 Pattison 2013, 570-576.

48 Pape 2011.

49 Luttwak 1999.

$50 \quad$ Brownlie 1974, 223. See Brown 2003 and Richemond 2003.
} 
means more comprehensive, and a wider variety of agents is responsible for delivering protection to groups needing it.

Advocacy for the Responsibility to Protect has helped reconcile protection imperatives with concerns for the integrity of state sovereignty. All versions of the principle locate the authority to mandate armed intervention with the Security Council, effectively foreclosing the possibility of unilateral intervention. Consequently, the Responsibility to Protect never threatened to undermine international order in the way that justifications for unilateral humanitarian intervention did. The explicit aim of ICISS was to find a way of conceptually reconciling the principle of state sovereignty with human protection norms. This was achieved by way of the "sovereignty as responsibility" formula that premised sovereignty on the ability and willingness to protect. The architects of the principle determined a number of conditions under which the principle of state sovereignty would yield to that of human rights protection. Since 2005, the narrower focus of the principle is on the four crimes outlined in the World Summit Outcome Document. According to the Responsibility to Protect, interference in the domestic affairs of states manifestly failing to protect is limited temporarily until the time the government resumes its full protection responsibilities and may be limited geographically to territories in which mass atrocities are occurring. ${ }^{51}$ Finally, with a range of alternative measures at the disposal of protection agents, including sanctions and diplomacy, and a greater variety of agents responsible for delivering protection, the traditional argument in defense of inconsistency suggesting that consistent humanitarianism could potentially undermine international order, similarly to the previous argument, has become more difficult to maintain.

\subsection{Virtue Ethics}

Another concern pertains to the extent to which principled intervention, or principled humanitarianism more generally, discourages "practical reason" in the Aristotelian sense; in other words, the extent to which it prioritizes process (meeting criteria, abiding by laws) over outcomes (in this case, meeting protection responsibilities). This argument is different in that it is not related to structure or the balance of power, but to agency - specifically, the process of reasoning and judgment. The argument outlines the problems inherent in deontological approaches. Brown, as well as Szende, argue that an approach characterized by attention to process, rather than outcome, interferes with an

51 Thakur 2019. 
agent's ability to appreciate the particularities of the case and its context. ${ }^{52}$ A deontological approach requires categorization-"cookie-cutter responses" to ethical dilemmas, ${ }^{53}$ discouraging the exercise of practical reason based on inference rather than deduction. ${ }^{54}$ Virtue ethics are therefore preferable over deontological approaches that necessarily inhibit the agent's ability to make prudential decisions.

However, while rules-based approaches necessarily run the risk of oversimplification, they also entail the possibility of accountability, which virtue ethics do not. What is more, the contemporary protection discourse and the practices associated with it offer a much richer repertoire of tools for delivering protection to populations in need; hence, they can be tailored more closely to case and context. While the Responsibility to Protect-like a plethora of intervention doctrines that precede the principle — cannot address the a priori objections to deontological approaches, given that just war thresholds as contained in the ICISS report, the "manifestly failing" threshold as articulated in the 2005 World Summit Outcome Document, or the three pillars framework as elaborated in the Secretary-General's report of 2009 all require deontological judgment. Principles, in essence, constrain innovation and the ability of agents to tailor their responses to specific needs. However, these recent efforts at articulating more elaborate and nuanced principles arguably represent a step in the right direction. The contemporary human protection regime is more focused, ${ }^{55}$ more elaborate, ${ }^{56}$ and more considerate of the alternatives to war. ${ }^{57}$

\subsection{Moral Hazard}

Finally, a fourth argument in defense of inconsistency is that predictable intervention may create a moral hazard. The term incorporates the word "moral" but it is an argument about the universalization of principles based on empirical observation of cause and effect, not a consequentialist argument about good judgment. Nevertheless, it is relevant here as the effects of moral haz-

$52 \quad$ Brown 2003; Szende 2012.

53 Bellamy and McLoughlin 2018, 180.

54 Brown suggests replacing the deontological approach with Aristotelian virtue ethics. "The Aristotelian notion of phronesis is always about the exercise of the faculty of reason." Brown 2012, 446.

It is more narrowly focused on a specific set of crimes listed in the World Summit Outcome Document: genocide, ethnic cleansing, war crimes, and crimes against humanity.

$5^{6}$ It recognized that crises giving rise to atrocities are complex. For example, Jennifer Welsh suggests the responsibility to protect is a "complex norm." Welsh 2014, 124.

For a comprehensive discussion of these alternatives, see Pattison 2018. 
ard may, if indeed such effects could be ascertained empirically, undermine the case for consistency (in terms of the absence of selectivity) on consequentialist grounds. The concept is taken from economic theory and, applied in the humanitarian domain, suggests that predictable coercive measures may affect the behavior of parties to a conflict. Predictable military intervention, it has been suggested, may spur rebellion, or intensify it, by lowering its cost and increasing its prospects of success. ${ }^{58} \mathrm{An}$ analogy is again useful here. Moral hazard suggests that insurance of property-for example, a bicycle - may incentivize the owner to be less cautious - by disincentivizing the owners to lock up their bicycle when unguarded. Moral hazard in conflict studies suggests that predictable third-party intervention can spur rebellion, or even encourage rebels to act in a way that risks or provokes government retaliation in the anticipation of third-party protective intervention; resulting in atrocities that would not otherwise occur. Some studies, however, suggest that moral hazard-the cumulative effect of reliable third-party intervention-performs poorly as an explanatory theory. 59

However, even if it can be empirically ascertained that reliable intervention produces adverse effects through moral hazard, the developing human protection regime may be able to mitigate the risk of moral hazard because the more comprehensive protection framework that is now in place means that armed intervention is but one of a range of coercive measures that third parties have at their disposal in responding to conflict and regime change is not necessarily a likely outcome. The international human protection regime outlines possibilities for case-specific conflict management and atrocity prevention, rather than simply "sending the Marines." ${ }^{20}$ Consequently, it is unlikely, in the future, that rebel groups will have sufficient certainty that collective responses would entail military intervention likely to promote rebel success. The more limited protection mandate at the center of the human protection regime means that protection is impartial (although not necessarily neutral), limited temporally, and potentially territorially, and eschews broader aims such as regime change, territorial change, or policy concessions; although, of course, longer-term, structural prevention objectives may include democracy promotion and addressing structural inequality. In short, the human protection regime does not facilitate war fighting. If third parties are seen to consistently engage in conflict management and atrocity prevention, rather than taking a partisan role-if rebels

$58 \quad$ Kuperman 2008.

59 Western 2005; Bellamy and Williams 2012.

6o Lee Feinstein, as quoted in G. Evans 2008, 292. 
cannot expect that intervention will lead to rebel success - the possibility of an incentive for recklessness or provocation, and hence the risk of moral hazard, is removed.

Recent scholarship has taken account of this perspective. Alan J. Kuperman suggests four strategies for mitigating the risk of moral hazard: ${ }^{61}$ avoiding partisan armed intervention; structural prevention through addressing legitimate grievances; timely, preventive protection intervention to mitigate the risk of atrocities; and the provision of humanitarian aid in a way that minimizes benefit to rebels ${ }^{62}$ - have been incorporated in the three pillar approach outlined in the 2009 report of the Secretary-General on implementing the Responsibility to Protect. ${ }^{63}$ In line with these principles, consistent international responses responses do not mean that identical measures will be taken in every case. Rather, consistent responses mean appropriate and timely collective action to prevent atrocities. When the consistent objective is to manage conflict and to deliver protection, rather than to win a war, none of the parties to a conflict can expect armed third-party intervention to bolster their chances of military success. Consequently, rebels cannot assume that provoking state repression will have the intended effect of armed intervention, and comprehensive, robust, and timely responses can mitigate the risk of atrocities early in a conflict.

Given this, the argument in defense of inconsistency on the grounds of moral hazard, like the preceding arguments in defense of inconsistency, has become less compelling. While consistent military intervention may, or may not, have perverse effects as suggested by moral hazard theory, consistent human protection - the discharge of protection responsibilities by a range of relevant actors, making full use the available repertoire of protection measures, both coercive and noncoercive—can have no such adverse effects.

Arguments in Defense of Consistency

The preceding discussion has engaged with several arguments in defense of selective humanitarian intervention. I have shown that these arguments are difficult to defend under closer scrutiny, especially in light of the emergence of a discourse of protection and responsibility and in the context of a nascent protection regime. First, the preceding discussion showed that changes in the

\footnotetext{
$61 \quad$ Kuperman 2008.

62 Kuperman 2008, 73 .

63 The 2009 report of the UN Secretary-General, "Implementing the Responsibility to Protect," is a good reflection of this development. UN General Assembly 2009.
} 
international discourse have begun to shift international expectations and robust responses by international actors to protect vulnerable populations from mass killing, gender-based violence, torture, forced disappearance, and other grave human rights violations committed systematically by governments or other actors are no longer viewed merely as a discretionary right; the emergence of the human protection regime has resulted in a shifting conceptualization of protection as a right, with corollary duties of the relevant international actors. When states fail to discharge the responsibilities conferred on them by their sovereignty, former UN Secretary-General Ban Ki-moon suggested at the annual Cyril Foster Lecture at Oxford in 2011, "the international community is morally obliged to consider its duty to act in the service of human protection." 64

Second, the contemporary protection discourse has depoliticized protection in the sense that the protection of individuals and collective groups is the primary objective and, although armed intervention may have a role to play in realizing this objective, it is not the only means by which human protection can be delivered. In fact, it is conceived of as a measure of last resort (if not necessarily a measure that must come last after all other measures have been exhausted). A host of measures, including noncoercive and nonmilitary coercive measures, is at international actors' disposal in delivering protection. Numerous landmark documents - the ICISS report, the World Summit Outcome Document, as well as the Secretary-General's annual reports on the responsibility to protect, among others - have continuously reiterated this and sought to disassociate protection from armed intervention. The idea of consistent protection does not imply the militarization of world politics-nor does it threaten to undermine state sovereignty or international order.

Third, if consistency is understood as the robust provision of protection to all those who need it, by whichever means best facilitate it, then practical reason can be reconciled with consistent humanitarianism. However, it is difficult to reconcile practical reason with consistency understood as rule-compliant behavior, given the potentially debilitating effects on an agent's capacity for practical judgment. However, changes in the development of policy over the past two decades mean that cookie-cutter approaches to conflict management are unlikely. The nascent human protection regime provides a more comprehensive and more refined approach to responding to protection crises and complex humanitarian emergencies - a significant departure from the cruder humanitarian intervention approach of the 199os. Also, while an Aristotelian

64 Ban 2011. 
practical reason approach may be preferable in theory, its utility in practice is doubtful, given that much depends on the judgment of agents with incomplete information, or lacking experience. Agents may be biased, or they may not be perceived as legitimate judges. Norms and the political maintenance of norms requires trust, and this is best facilitated through predictable, rulesbased governance and mechanisms of accountability. Practical reason, in contrast, impedes the institutionalization of norms.

Finally, the preceding discussion has also questioned the salience of the moral hazard argument, suggesting that this, similarly, becomes difficult to defend in light of the emergence of the protection discourse. The wider range of measures available to relevant actors means that protection is no longer equated with armed intervention, but understood as carefully crafted, internationally coordinated responses to conflict and complex emergencies. The measures selected to meet these protection responsibilities will vary depending on case and context, but the protection regime suggests that actions ought to be consistent in terms of the objective of delivering protection to all those in need of protection, as well as in terms of their conformity with international norms and international law. Given the replacement of humanitarian intervention with the broader human protection discourse, the moral hazard logic is no longer applicable and, for that reason, cannot serve to justify inconsistency.

The survey of the four traditional arguments about consistency in the context of the humanitarian intervention debate has shown that these arguments have become less compelling than they may have been in the past. In these circumstances, and by way of conclusion, it is worth briefly expounding the a priori position in favor of consistency, and how it relates to responsibility and protection in the current international context. These fall into two main categories: arguments about the implications of inconsistency for the development of international norms on the one hand, and consequentialist arguments about the effects of inconsistent provision of protection to vulnerable populations on the other.

\subsection{Inconsistency and the Human Protection Regime}

The rules structuring social relations would be questioned if they were not applied consistently. Some exceptions may be legitimate, and aberrations that result from norm contestation play a crucial role in developing norms. Similarly, aberrations resulting from norm collisions play a crucial role in developing norms systems. However, aberrations resulting from unfair discrimination or negligence can lead to norm corrosion or obsolescence. For example, Christopher Kutz illustrates how internalized norms prohibiting torture and 
assassination have crumbled in the context of the "global war on terror."65 Kutz suggests that force-constraining norms stand a better chance of survival when they are "internalised by coherent and relatively insulated professional cadres who see themselves as needing to act consistently over time." ${ }^{66}$ In other words, institutions and bureaucracies that promote the consistent application of norms can preserve or nurture these norms. The validity of a norm depends on its intersubjective relevance. For a rule to be meaningful it must, at the very least, apply in broadly the same way, most of the time. Hence, norms first need to be coherent - that is, they must align with other norms and fit into a broader normative system — and, second, they must be applied consistently; in other words, they should not apply selectively. Consequently, inconsistent protection practices impede the prospects for the development of the international human protection regime; the continued development of the protection regime critically depends on the consistent practice of the norms associated with it.

\subsection{Inconsistency and Disparities in Protection}

Inconsistent practice violates the principle of distributive justice, and, from a consequentialist perspective, inconsistent practice means that fewer people receive protection from egregious violations of human rights than they would if international practice were consistent. On these grounds alone, a principled defense of inconsistency is therefore untenable. Rather than bringing ethical arguments in line with practical realities, international actors ought to aspire to shape international practice in such a way so as to facilitate principled action. This entails continued efforts at norm advocacy and institution building. A principled defense of consistency is not irreconcilable with the recognition that the international context presently inhibits the realization of consistent protection but, on the contrary, should be seen as a starting point for further reflection on what can be done to bring about an international environment that facilitates consistent protection.

In the Aristotelian sense, consistency requires humanitarian principles to be internally consistent - they must be sound, with few contradictions. "Coher-

$65 \quad$ Kutz 2014, 425 .

66 Kutz 2014, 426. 
ence" may be another way of describing this form of consistency. Coherence is a prerequisite for procedural consistency; that is, the equal application of principles, without aberration. Contemporary human rights advocacy and campaigns that make use of concepts such as human security and the responsibility to protect reflect the desire by policymakers and practitioners to establish an environment that is more conducive to such principles-based humanitarianism and consistent human protection. They reflect a desire to improve the coherence of the normative regime underpinning international humanitarianism. They aim to advance the international human protection regime, to compel actors tasked with protection to provide consistent protection to populations in need.

In the wake of the Blair Doctrine, "selectivity," for a while at least, ceased to be a derogatory descriptor. The international discourse appeared to be receptive to the idea that interventions could be both self-interested and just, ${ }^{67}$ and that selectivity was not only unavoidable in practical terms, but that it could also be reasonable in ethical terms. Since then, a majority of scholars in the field have defended selective humanitarianism on practical grounds. However, I have argued above that the validity of these arguments-focusing specifically on the effect of consistent intervention on international order, the relationship with moral agency, the relationship with moral hazard, and arguments about duties and obligations - should be reconsidered in light of the growing influence of the protection discourse. Within a developing normative framework that is organized around the welfare of individuals and groups, rather than the interests of states and the survival of sovereigns, ${ }^{68}$ a position in defense of inconsistency becomes difficult to maintain. Nonprotection, understood as the evasion of protection duties, is a norm transgression in its own right within the human protection regime.

Several conclusions follow from the arguments outlined above. First, if consistency serves as a moral imperative, although international responses to humanitarian emergencies remain inconsistent, norm advocates must redouble their efforts at consensus building and conceptual refinement of the principles governing humanitarian action. This calls for reflection on what is required for laying the groundwork for accountability and enforceability and for creating the institutional architecture necessary for realizing humanitarian objectives. Policymakers and scholars should place renewed emphasis on the coherence of humanitarian principles, especially regarding their legal status and their

67 Brown 2010, 215.

68 Ramesh Thakur refers to this as a "Feuerbachian inversion." Thakur 2019, 78-94. 
relationship with other norms, and consider ways of changing international institutions and practices so as to allow for greater consistency in the application of these principles.

Second, inconsistent practice impedes the development of human protection principles. International practice that is inconsistent with international law-either failing to meet protection responsibilities where protection is imperative, as was the case for Rwandan genocide, or failing to act in line with established principles of international law, as was the case when NATO intervened in Kosovo without the authorization of the Security Councilundermines the credibility of the protection regime and the prospects for its further development. Domestically, the rule of law affords protection to all regardless of status and wealth. The same ought to apply internationally, where a rules-based protection regime "is a better normative protection instrument than the unilateralism of humanitarian intervention." 69 States and other actors should therefore support the development of the human rights and human protection regimes, and support the principles and institutions associated with them. Where they are perceived as lacking capacity or legitimacy, these same actors should work together to find ways of addressing both issues.

The human protection regime entails prescriptive as well as proscriptive elements. ${ }^{70}$ It entails protection duties, but also proscribes that these must be discharged in accordance with other international norms, notably Security Council authorization of measures that lack the consent of a state manifestly failing in its protection responsibilities. The proscriptive and prescriptive elements of the regime have resulted in criticism that the regime is self-contradictory, incoherent, or ambiguous, resulting in greater scope for double standards and misuse. Roland Paris refers to this as a structural problem, a "logical trap" of states' own making. ${ }^{71}$ However, consistency as reliable protection across cases on the one hand, and consistency as responses that also conform with other international principles on the other, are not contradictory, but mutually reinforcing. Consistent practice in line with international law strengthens collective trust in the human protection regime. Narrower protection objectives also avoid the further escalation of hostilities and open up more possibilities for peaceful resolutions of conflicts that lie at the root of humanitarian emergencies. Unilateral intervention, in contrast, sets precedents that weakens trust in the regime, thereby lessening the ability of the regime to provide a framework for principles-guided responses in future cases. Vice versa, reliable protection

69 Thakur 2019, 114.

$70 \quad$ This can be referred to as a "licence," as well as a "leash." Doyle 2016.

71 Paris 2014. 
serves as a normative premise that ought to condition our thinking about ways in which human protection norms can be developed further.

Consequently, moving from a context that predisposes international humanitarianism to the selective application of principles to one in which protection is implemented consistently requires continued efforts at lawmaking and norm entrepreneurship. This, in turn, entails persuading target audiences and influencing the international discourse. Some of this conceptual groundwork has been accomplished, but persisting ambiguities and incoherence within the developing protection regime complicate the implementation of the principles associated with it. Addressing these ambiguities is a first step toward principlesguided, consistent responses to humanitarian crises. Less selectivity, and more consistency, may in turn help lay the foundations of a more responsible and just international society.

\section{Bibliography}

Annan, Kofi. "Two Concepts of Sovereignty." The Economist, 18 September 1999.

Arbour, Louise. "The Responsibility to Protect as Duty of Care in International Law and Practice." Review of International Studies 34 (2008), No. 3, 445-458.

Aristotle. Metaphysics, Volume I: Book 4, trans. Hugh Tredennick (Cambridge: Harvard University Press, 1933).

Ban Ki-moon. "Human Protection and the 21st Century United Nations." Cyril Foster Lecture, University of Oxford, 2 February 2011. https://www.un.org/sg/en/content/ $\mathrm{sg} /$ speeches/2011-02-02/cyril-foster-lecture-oxford-university-human-protection-a nd-21st.

Barnett, Michael. “The Humanitarian Club.” Keynote Lecture, Global Governance Institute, University College London, 5 February 2019.

Bellamy, Alex. "Whither the Responsibility to Protect? Humanitarian Intervention and the 2005 World Summit." Ethics and International Affairs 20 (2006), Issue 2, 143-169.

Bellamy, Alex. "The Responsibility to Protect and the Problem of Military Intervention." International Affairs 84 (2008), No. 4, 615-639.

Bellamy, Alex. "The Humanisation of Security? Towards an International Human Protection Regime." European Journal of International Security 1 (1) (2016), 112-133.

Bellamy, Alex J., and Stephen McLoughlin. Rethinking Humanitarian Intervention (Palgrave, London, 2018).

Bellamy, Alex, and Paul D. Williams. "The New Politics of Protection? Côte d'Ivoire, Libya and the Responsibility to Protect." International Affairs 87 (2011), Issue 4, 825850 .

Bellamy, Alex, and Paul D. Williams. "On the Limits of Moral Hazard:The 'Responsibility 
to Protect', Armed Conflict and Mass Atrocities." European Journal of International Relations 18 (2012), Issue 3, 539-571.

Binder, Martin. "Humanitarian Crises and the International Politics of Selectivity." Human Rights Review 10 (2009), 327-348.

Björkdahl, Annika. "Norms in International Relations: Some Conceptual and Methodological Reflections." Cambridge Review of International Affairs 15 (2002), Issue 1, 9-23.

Brilmayer, Lea. "What's the Matter with Selective Intervention?" Arizona Law Review 37 (1995), Issue 4, 954-970.

Brown, Chris. "Selective Humanitarianism: In Defence of Inconsistency." In Ethics and Foreign Intervention, eds. Deen Chatterjee and Don Scheid (Cambridge: Cambridge University Press, 2003), 31-5o.

Brown, Chris. "On Morality, Self-Interest and Foreign Policy." In Practical Judgment in International Political Theory: Selected Essays (Routledge, Abingdon, Oxon, 2010), 221-235, 215.

Brown, Chris. “The 'Practice Turn', Phronesis and Classical Realism: Towards a Phronetic International Political Theory?" Millennium:Journal of International Studies 40 (2012), Issue 3, 439-456.

Brownlie, Ian. "Humanitarian Intervention." In Law and Civil War in the Modern World, ed. John Norton Moore (Lawbook Exchange, Baltimore and London, 1974), 217228.

Cambridge Dictionary. s.v. "consistency." 2019. http://dictionary.cambridge.org/dictiona ry/english/consistency.

Chayes, Abram, and Antonia Handler Chayes. The New Sovereignty: Compliance with International Regulatory Agreements (Cambridge: Harvard University Press, 1995).

Crossley, Noele. Evaluating the Responsibility to Protect: Mass Atrocity Prevention as a Consolidating Norm in International Society (Abingdon: Routledge, 2016).

Damrosch, Lori Fisler. "The Inevitability of Selective Response? Principles to Guide Urgent International Action." In Kosovo and the Challenge of Humanitarian Intervention: Selective Indignation, Collective Action, and International Citizenship, eds. Albrecht Schnabel and Ramesh C. Thakur (Tokyo: United Nations University Press, 2000), 405-419, 414.

Doyle, Michael W. "The Politics of Global Humanitarianism: ${ }_{2} \mathrm{P}$ before and after Libya." In Oxford Handbook of the Responsibility to Protect, eds. Alex Bellamy and Tim Dunne (Oxford: Oxford University Press, 2016), Part VI.

Evans, Gareth. "Rethinking Collective Action: The Responsibility to Protect and Duty to Prevent." American Society of International Law Proceedings 98 (2004), 77-94.

Evans, Gareth. "The Responsibility to Protect: An Idea Whose Time Has Come ... and Gone?" International Relations 22(3), 283-298.

Evans, Mark. "Selectivity, Imperfect Obligations and the Character of Humanitarian 
Morality." In Human Rights and Military Intervention, eds. Alexander Moseley and Richard Norman (Ashgate, Abingdon, Oxon, 2002), 132-152.

Fabre, Cécile. Economic Statecraft: Human Rights, Sanctions, and Conditionality (Cambridge: Harvard University Press, 2018).

Glanville, Luke. "The Responsibility to Protect beyond Borders." Human Rights Law Review 12 (2012), Issue 1, 1-32.

Hehir, Aidan. "The Permanence of Inconsistency: Libya, the Security Council, and the Responsibility to Protect." International Security 38 (2013), Issue 1, 137-159.

International Commission on Intervention and State Sovereignty. "The Responsibility to Protect" (Ottawa, Ontario, Canada: International Development Research Centre, 2001).

International Law Commission. "Fragmentation of International Law: Difficulties Arising from the Diversification and Expansion of International Law." Report No. A/CN.4/L.682 (International Law Commission, 2006).

Kelsen, Hans. "Pure Theory of Law" (Berkeley: University of California Press, 1967).

Kikoler, Naomi. "Responsibility to Protect." Keynote paper presented at the conference "Protecting People in Conflict and Crisis: Responding to the Challenges of a Changing World," Oxford University, September 2009.

Kuperman, Alan J. "The Moral Hazard of Humanitarian Intervention: Lessons from the Balkans." International Studies Quarterly $5^{2}$ (2008), Issue 1, 49-8o.

Kutz, Christopher. "How Norms Die: Torture and Assassination in American Security Policy." Ethics and International Affairs 28 (2014), Issue 4, 425-449.

Labonte, Melissa. "Whose Responsibility to Protect? The Implications of Double Manifest Failure for Civilian Protection." International Journal of Human Rights 16 (2012), Issue 7, 982-1002.

Luttwak, Edward. “Kofi's Rule: Humanitarian Intervention and Neocolonialism.” The National Interest, 1 December 1999, 57-62.

Milanovic, Marko. “Norm Conflict in International Law: Whither Human Rights?" Duke Journal of Comparative and International Law 20 (2009), Issue 1, 69-131.

Oberman, Kieran. "The Myth of the Optional War: Why States Are Required to Wage the Wars They Are Permitted to Wage." Philosophy and Public Affairs 43 (2015), Issue 4, $255^{-286 .}$

Pape, Robert A. "The New Standard for Humanitarian Intervention." The Atlantic, 4 April 2011.

Paris, Roland. "The 'Responsibility to Protect' and the Structural Problems of Preventive Humanitarian Intervention." International Peacekeeping 21 (5) (2014), 569-6o3.

Pattison, James. "Whose Responsibility to Protect? The Duties of Humanitarian Intervention." Journal of Military Ethics 7 (4) (2008), 262-283.

Pattison, James. "Is There a Duty to Intervene? Intervention and the Responsibility to Protect." Philosophy Compass 8 (6) (2013), 570-576. 
Pattison, James. The Alternatives to War (Oxford: Oxford University Press, 2018).

Richemond, Daphné. "Normativity in International Law: The Case of Unilateral Humanitarian Intervention." Yale Human Rights and Development Law Journal 6 (2003), $45^{-80 .}$

Roberts, Adam. "The So-Called "Right" of Humanitarian Intervention." Yearbook of International Humanitarian Law 3 (2000), 3-51.

Singer, Peter. "Famine, Affluence, and Morality." Philosophy and Public Affairs 1 (3) (1972), 229-243.

Slater, Jerome, and Terry Nardin. "Nonintervention and Human Rights." Journal of Politics 48 (1) (1986), Issue 1, 86-96.

Steyn, Karen. “Consistency-A Principle of Public Law?” Judicial Review 2 (1) (1997), 22-26.

Szende, Jennifer. "Selective Humanitarian Intervention: Moral Reason and Collective Agents." Journal of Global Ethics 8 (1) (2012), 63-76.

Thakur, Ramesh. Reviewing the Responsibility to Protect: Origins, Implementation and Controversies (Abingdon: Routledge, 2019).

UN General Assembly. "Implementing the Responsibility to Protect." Report of the Secretary-General. UN Doc. A/63/677 (12 January 2009).

Vranes, Erich. “The Definition of 'Norm Conflict' in International Law and Legal Theory." European Journal of International Law 17 (2) (2006), Issue 2, 395-418.

Weiss, Thomas G. "Halting Genocide: Rhetoric versus Reality." Genocide Studies and Prevention: An International Journal 1 (2007), Vol. 2, 6-30.

Welsh, Jennifer. "From Right to Responsibility: Humanitarian Intervention and International Society." Global Governance 8 (2002), Issue 4, 503-521.

Welsh, Jennifer. "Implementing the 'Responsibility to Protect': Catalyzing Debate and Building Capacity." In Implementation and World Politics: How International Norms Change Practice, eds. Alexander Betts and Phil Orchard (Oxford: Oxford University Press, 2014), 124-143.

Western, Jon. "Illusions of Moral Hazard: A Conceptual and Empirical Critique." Ethnopolitics 4 (2) (2005), 225-236.

Wheeler, Nicholas J. Saving Strangers: Humanitarian Intervention in International Society (Oxford: Oxford University Press, 20oo). 